\title{
WEB Treatment of Ruptured Intracranial Aneurysms: A Single-Center Cohort of 100 Patients
}

\author{
(D) S.B.T. van Rooij, (DW.J. van Rooij, (D).P. Peluso, (D) M. Sluzewski, DR.S. Bechan, (DH.G. Kortman, (D) G.N. Beute, \\ (D) B. van der Pol, and IDC.B. Majoie
}

\begin{abstract}
BACKGROUND AND PURPOSE: The Woven EndoBridge device was recently introduced for the intrasaccular treatment of wide-neck aneurysms without the need for adjunctive devices. We present our results of the primary treatment of ruptured aneurysms with the Woven EndoBridge regardless of location or neck size.
\end{abstract}

MATERIALS AND METHODS: Between February 2015 and April 2017, 100 ruptured aneurysms were selectively treated with the Woven EndoBridge. No supporting stents or balloons were used. There were 71 women treated (mean patient age, 59 years; median age, 60 years; range, 23-82 years).

RESULTS: The mean aneurysm size was $5.6 \mathrm{~mm}$ (range, 3-13 mm), and 42 aneurysms were $\leq 4 \mathrm{~mm}$. Sixty-six aneurysms (66\%) had a wide neck, defined as $\geq 4 \mathrm{~mm}$ or a dome-neck ratio $\leq 1.5$. There was 1 procedural rupture without sequelae. In 9 patients $(9 \%)$, thromboembolic complications occurred. One poor grade patient died; neurologic deficits remained in 3. Overall treatment-related morbidity-mortality was $4 \%$ (4 of $100 ; 95 \% \mathrm{Cl}, 1.2 \%-10.2 \%)$.

Two of 100 aneurysms were initially incompletely occluded and were additionally treated early after initial intervention. Of 80 eligible patients, 74 (93\%) had 3-month angiographic follow-up. Fifty-four aneurysms (73\%) were completely occluded, 17 (23\%) had a small neck remnant, and $3(4 \%)$ were incompletely occluded. One patient was additionally treated with a second Woven EndoBridge, and in 2 patients, additional treatment is scheduled. The overall reopening/retreatment rate was $6.8 \%(5$ of $74 ; 95 \% \mathrm{Cl}$, $2.6 \%-15.2 \%)$. There were no rebleeds during follow-up.

CONCLUSIONS: Treatment of small ruptured aneurysms with the Woven EndoBridge was safe and effective. The Woven EndoBridge proved to be a valuable alternative to coils without the need for stents or balloons.

ABBREVIATION: WEB $=$ Woven EndoBridge

E dovascular treatment of wide-neck intracranial aneurysms with coils mostly requires the use of a temporary protection balloon or a stent. However, this makes the procedure more complicated with a higher chance of complications. ${ }^{1-4}$ With stents, periprocedural dual antiplatelet therapy is required and has to be prolonged for 3-6 months. With this antiaggregation regimen, stent-assisted coiling in ruptured aneurysms has a higher inherent risk for early rebleed or hemorrhage in the postoperative period.

Received May 9, 2017; accepted after revision July 7.

From the Department of Radiology (S.B.T.v.R.), Noordwest Ziekenhuisgroep, Alkmaar, the Netherlands; Departments of Radiology (W.J.v.R., J.P.P., M.S., R.S.B., H.G.K.), and Neurosurgery (G.N.B., B.v.d.P.), Elisabeth Tweesteden Ziekenhuis, Tilburg, the Netherlands; and Department of Neuroradiology (C.B.M.), Academisch Medisch Centrum, Amsterdam, the Netherlands.

Please address correspondence to W.J. van Rooij, MD, PhD, Department of Radiology, Elisabeth Tweesteden Ziekenhuis, Hilvarenbeekseweg 60, 5022GC Tilburg, the Netherlands; e-mail: wjjvanrooij@gmail.com

http://dx.doi.org/10.3174/ajnr.A5371
Despite antiaggregation, thromboembolic complications still occur. ${ }^{5}$

Recently, the intrasaccular flow disruptor Woven EndoBridge (WEB; Sequent Medical, Aliso Viejo, California) device has been developed, primarily for the treatment of (bifurcation) wide-neck aneurysms without the need for adjunctive devices. The first clinical results of the WEB device show good safety and efficacy profiles. Most of the published series comprised wide-neck, unruptured aneurysms. ${ }^{6-24}$

In a previous publication, we presented our first results of the use of the WEB for all ruptured aneurysms suitable for the device, regardless of location or neck size. ${ }^{25}$ Our intention was to avoid stents in the treatment of ruptured aneurysms. Our strategy was to treat ruptured wide-neck aneurysms with the WEB or, when WEB placement was not possible, with coiling or surgery. In this study, we present the results of this treatment strategy with an extended cohort of 100 patients with ruptured aneurysms treated with the WEB. 


\section{MATERIALS AND METHODS}

This observational study with prospectively collected data was compliant with our institutional privacy policy. The institutional review board gave exempt status for approval and informed consent. The study was performed in the Elisabeth Tweesteden Ziekenhuis in Tilburg, the Netherlands.

\section{The WEB}

The Woven EndoBridge system is a self-expanding, spherical or pumpkin-shaped, braided mesh of platinum-cored nitinol wires that can be deployed in the aneurysm sac. The design of the WEB device has evolved from a dual-layer configuration (WEB-DL) to a single-layer version (WEB-SL) with a higher number of nitinol wires. The WEB-SL device is available in diameters ranging from 4-11 $\mathrm{mm}$ and heights ranging from 3-9 $\mathrm{mm}$. The WEB-SLS (Single-Layer Sphere) has a spherical shape and is available in diameters ranging from $4-11 \mathrm{~mm}$, each with a fixed height ranging between 2.6 and $9.6 \mathrm{~mm}$. The WEBs with diameters of 4-7 mm can be delivered through a 0.021 -inch internal diameter microcatheter, the WEBs with diameters of $8-9 \mathrm{~mm}$ through a 0.027 inch microcatheter, and the WEBs with diameters of $10-11 \mathrm{~mm}$ through a 0.033-inch microcatheter (VIA 21, 27, and 33; Sequent Medical). Recently, a lower-profile range of WEBs compliant with a 0.017-inch microcatheter (VIA 17) has become available in clinical practice.

Placed in the aneurysm, the WEB modifies the blood flow at the level of the neck and induces aneurysmal thrombosis. The WEB can be fully retrieved until final detachment by an electrothermal detachment system contained in a hand-held controller.

\section{General Indications in This Study}

In our institution, the treatment of patients with ruptured aneurysms is primarily endovascular within 24 hours after admission. Because of previous poor results with stent-assisted coiling in ruptured aneurysms, ${ }^{5}$ from January 2015 onwards, we decided not to use stents with inherent antiplatelet medication anymore. Wideneck aneurysms were treated either with the WEB, with coiling, or by surgery. Surgery was always an option in good grade patients with wide-neck anterior circulation aneurysms. In poor grade patients with wide-neck aneurysms not suitable for endovascular treatment, surgery was generally postponed several days.

The WEB device was initially developed for the treatment of wide-neck intracranial aneurysms as an alternative to balloon- or stent-assisted treatment. After our first encouraging experiences in unruptured wide-neck aneurysms, during the study period, we gradually expanded the indication to all aneurysms suitable for the WEB regardless of neck size, location, or rupture status. Examples of WEB treatment of ruptured aneurysms are provided in Figs 1-3.

Under general anesthesia, a microcatheter was advanced into the aneurysm via a coaxial or triaxial approach. Hence, the aneurysm was occluded with coils or with a WEB. The WEB was slightly oversized according to recommendations of the manufacturer. WEB sizes and shapes were recorded. Apart from heparin in the pressure bags for flushing (1000 IU/L), no anticoagulation was used.

Patient demographics and treatment and aneurysm character-

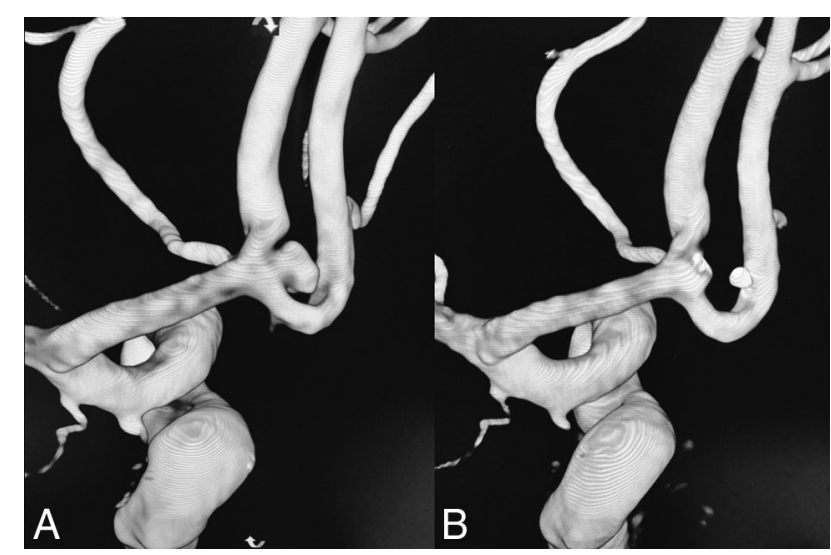

FIG 1. Ruptured anterior communicating artery aneurysm in a 52year-old man treated with the WEB. A, 3-mm aneurysm with a relatively small neck treated with a WEB Single-Layer Sphere $(4 \mathrm{~mm})$. $B$, 3-month follow-up angiogram shows complete occlusion.

istics were collected. Clinical grading during admission was according to the Hunt and Hess scale, and clinical follow-up was classified in mRS. For surviving patients, angiographic follow-up was scheduled at 3 months and 3T MRA follow-up at 6 months.

Quantitative variables were expressed with descriptive statistics, and categoric variables were expressed as frequencies or percentages with $95 \%$ CIs.

\section{RESULTS}

\section{Patients}

Between February 2015 and April 2017, 242 patients with a ruptured aneurysm were treated in our institution (Fig 4). Of 242 aneurysms, $189(78 \%)$ were treated with endovascular techniques, and 104 of those were treated with the WEB device. Four patients with vertebral dissection aneurysms were treated with parent vessel occlusion by using the WEB, and these were excluded from further analysis. The remaining 100 patients with ruptured aneurysms selectively treated with the WEB form the subject of this study.

There were 29 men and 71 women, with a mean age of 59 years (median, 60 years; range, 23-82 years). The clinical condition at the time of treatment was Hunt and Hess $1-2$ in 53 patients, 3 in 24 patients, and $4-5$ in 23 patients. The timing of treatment after SAH was $0-1$ day in 77 patients, $2-4$ days in 16 patients, and $>4$ days in 7 patients. The aneurysm location was the anterior communicating artery in 46 patients, the posterior communicating artery in 22 patients, the MCA in 16 patients, the pericallosal artery in 7 patients, the basilar tip in 5 patients, the superior cerebellar artery in 2 patients, the carotid tip in 1 patient, and the vertebral artery in 1 patient. The mean aneurysm size was $5.6 \mathrm{~mm}$ (median, $5 \mathrm{~mm}$; range, $3-13 \mathrm{~mm}$ ), and 42 aneurysms were $\leq 4$ $\mathrm{mm}$. Of 100 aneurysms, $66(66 \%)$ had a wide neck, defined as $\geq 4$ $\mathrm{mm}$ or a dome-neck ratio $\leq 1.5$. Four patients had 1 additional unruptured aneurysm treated in the same session, 1 with WEB and 3 with coils. One patient had 3 additional unruptured aneurysms treated with the WEB in the same session.

\section{Initial Results and Complications}

After WEB placement with sealing of the aneurysm neck, the position of the WEB inside the aneurysm was judged as good in 98 of 


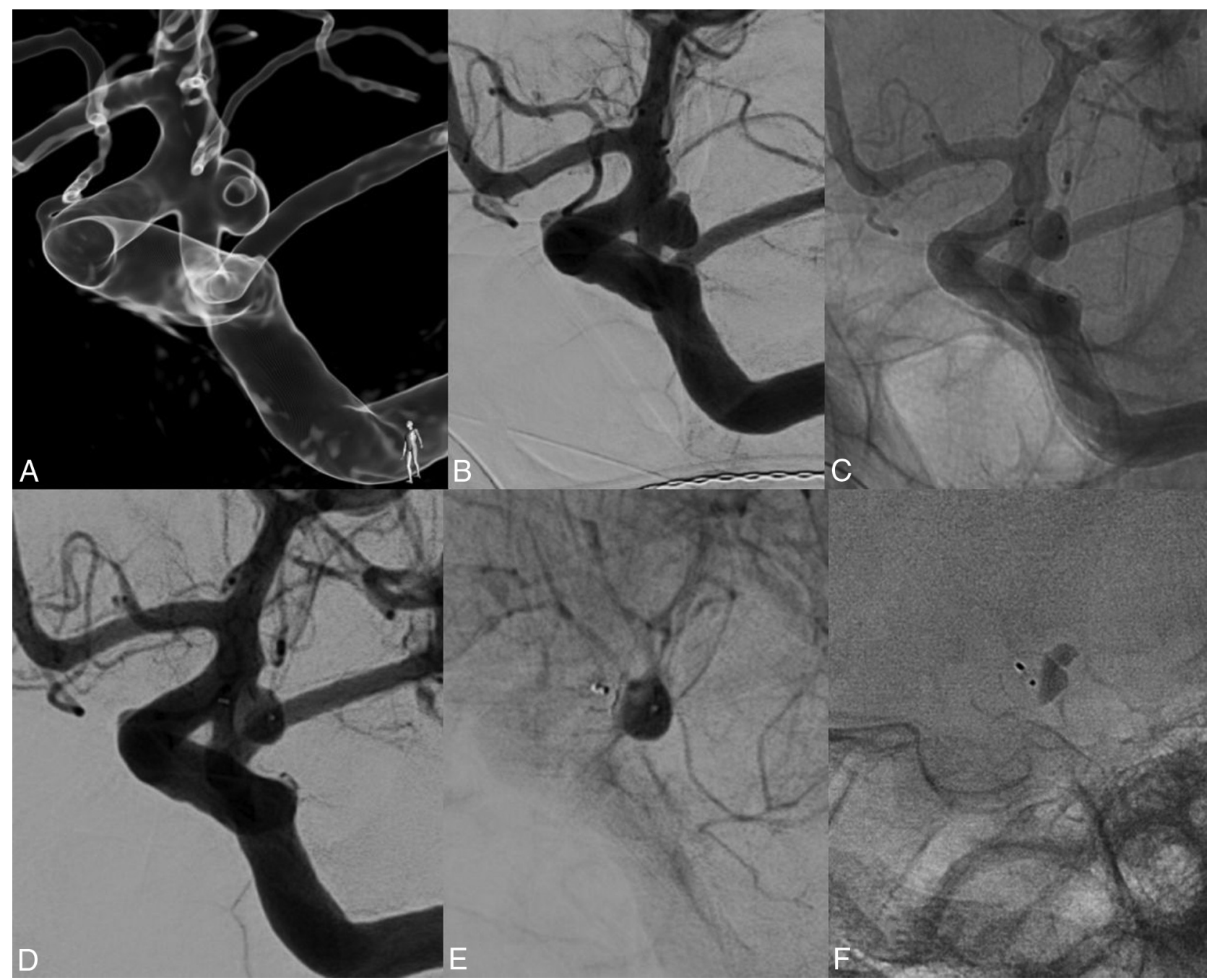

FIG 2. Ruptured wide-neck posterior communicating artery aneurysm in a 62 -year-old woman. $A, 3 D$ and $B, 2 D$ angiograms of a small wide-neck aneurysm on a fetal posterior cerebral artery. Note 2 blebs on the aneurysm. $C$ and $D$, The WEB fills the aneurysm with bridging of the neck. $E$ and $F$, Contrast stasis in the aneurysm after WEB placement.

100 aneurysms, without filling of aneurysm remnants. In 1 patient with a 13-mm ruptured pericallosal artery aneurysm, a WEB was placed to protect the dome only. This aneurysm was later additionally clipped. In 1 patient, the WEB was undersized, but this was only noticed after detachment. Follow-up angiography after 1 week showed an aneurysm remnant that was then occluded with coils.

In 2 patients, coils were placed in the aneurysm dome through a jailed second microcatheter before detachment of the WEB.

WEB sizes and shapes used are displayed in Fig 5. Most WEBs used (91 of 100) were in the smaller ranges suitable for the VIA 21 microcatheter, and the most frequently used size was $4 \mathrm{~mm}$ (43 of 100).

There was 1 procedural rupture by puncture of the dome of a posterior communicating artery aneurysm with the undeployed WEB. The bleeding stopped after WEB deployment; the patient remained unchanged in good grade. In 9 patients, thromboembolic complications occurred. In 7 of those 9 patients, thrombus was present before WEB placement. Five patients were treated with thrombosuction (followed by tirofiban in 2) and 4 with tirofiban only. One poor grade patient with incomplete result after thrombosuction developed a partial MCA infarction and died (mortality, 1 of 100 [1\%]). Neurologic deficits remained in 3 patients with outcomes of mRS 3 in 2 patients and mRS 2 in 1 patient (morbidity, 3 of 100 [3\%]). In 1 patient, catheterization caused a dissection of the internal carotid artery, which was successfully treated with a stent. Overall treatment-related permanent morbidity-mortality was $4 \%$ (4 of 100; 95\% CI, 1.2\%-10.2\%).

\section{Clinical Follow-Up}

Of 100 patients, 17 died during hospital admission of the sequelae of SAH. Of these 17 patients, 15 were admitted in poor grade (Hunt and Hess 4-5) and 2 in Hunt and Hess 3. One other poor grade patient died after a thromboembolic complication in an M2 branch during treatment led to partial right frontal brain infarction. Clinical follow-up in the 82 patients who survived the hospital admission period was mRS $0-2$ in 75 patients and mRS 3-5 in 7 patients. There were no rebleeds from the ruptured aneurysm during follow-up.

\section{Angiographic Follow-Up}

Two patients had early additional treatment of the WEB-treated ruptured aneurysm. Of the remaining surviving 80 patients, 74 (93\%) had 3-month angiographic follow-up. Three patients re- 


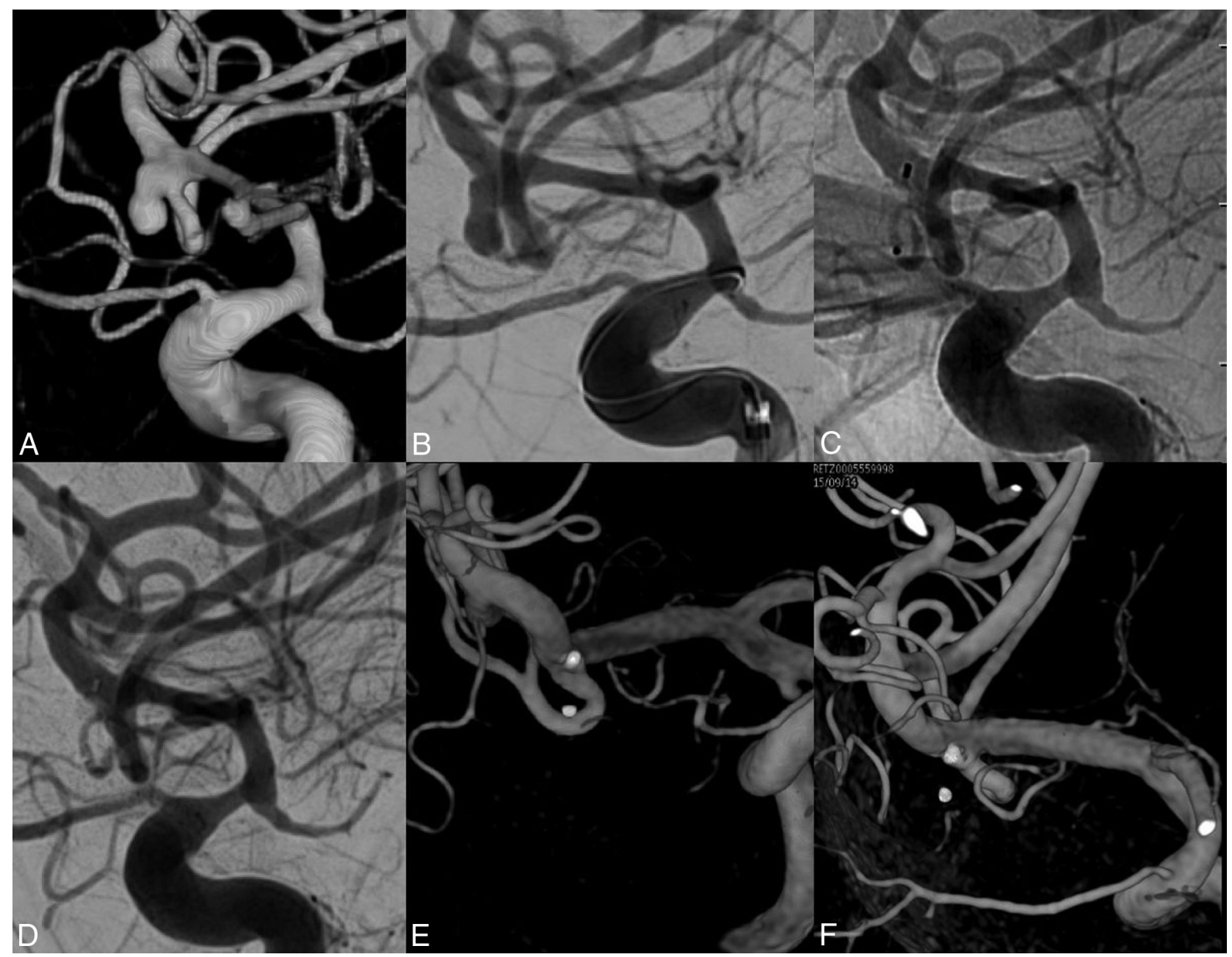

FIG 3. Small ruptured MCA aneurysm in a 58-year-old woman. $A, 3 D$ and $B, 2 D$ angiograms show downward-pointing small $M C A$ aneurysm. $A$, Native and $B$, subtracted angiogram after WEB placement. $E$ and $F, 3 D$ angiogram at 3 months shows persistent complete occlusion.

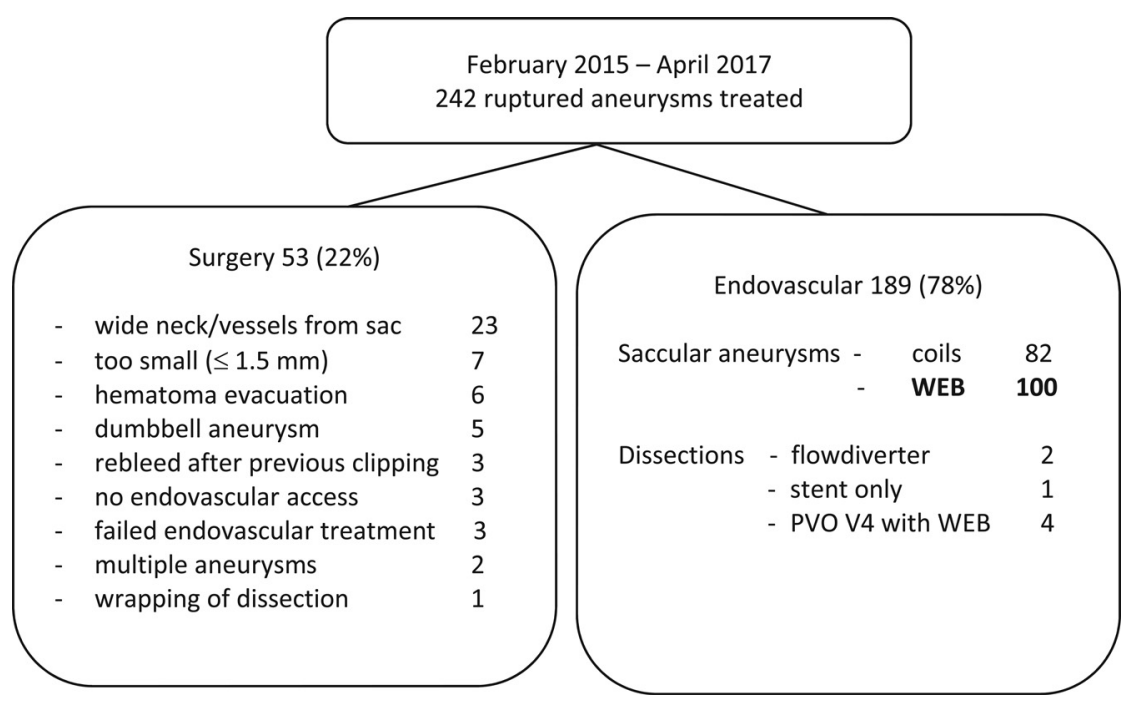

FIG 4. Flow chart of 242 ruptured aneurysms treated between February 2015 and April 2017, including main reasons to proceed to surgery. PVO indicates parent vessel occlusion; $\mathrm{V} 4$, vertebral artery segment 4.

fused follow-up angiography. In 3 patients, imaging follow-up is pending. Of the 74 patients with angiographic follow-up, 54 aneurysms $(73 \%)$ were completely occluded, 6 of those with some proximal WEB recess filling. ${ }^{26-28}$ Seventeen aneurysms (23\%) had a small neck remnant. In 3 patients (4\%), the aneurysm was incompletely occluded. In 1 of those 3 patients, the aneurysm remnant was additionally treated with a second WEB, and in 2 patients, additional treatment is scheduled. The reopening/retreatment rate was $6.8 \%$ (5 of $74 ; 95 \%$ CI, 2.6\%-15.2\%).

\section{DISCUSSION}

Our results show that we succeeded in our primary aim to avoid the use of stents in the treatment of acutely ruptured aneurysms by introducing the WEB. No stents were used in the endovascularly treated ruptured aneurysms, and in coiled ruptured aneurysms, even balloon assistance was not used. One might argue that a larger proportion of wide-neck aneurysms were allocated to surgery. However, fewer than 1 in 10 ruptured aneurysms (23 of 242) were referred to surgery for anatomic rea- 
WEB sizes in 100 ruptured aneurysms

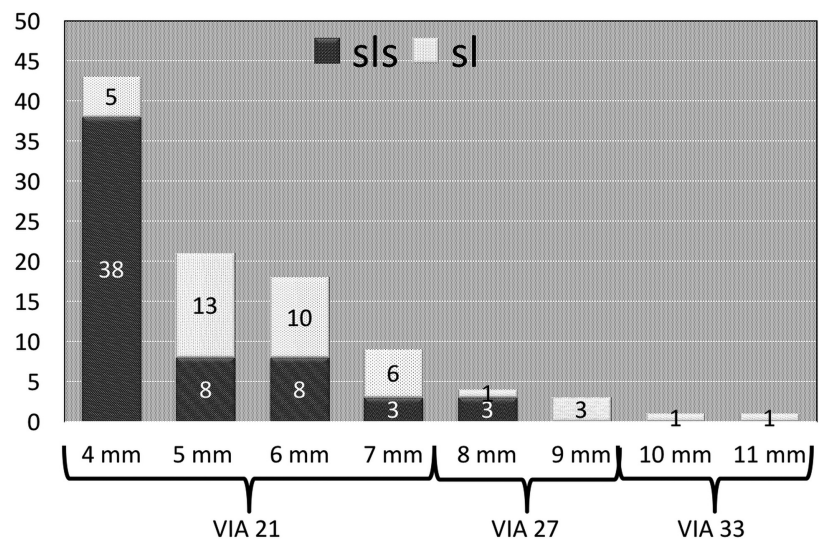

FIG 5. WEB sizes and shapes used in 100 ruptured aneurysms. VIA indicates the microcatheter used.

sons, mostly because of branches coming from the aneurysm sac or aneurysms with limited height (over wide or under tall). ${ }^{29}$ In our practice, $78 \%$ of ruptured aneurysms were treated endovascularly. This proportion is higher than the $66 \%$ from a recent survey in Germany. ${ }^{30}$ This indicates that the avoidance of the use of stents by introduction of the WEB was probably not counterweighted by increased referral to surgery.

With the use of stents in ruptured aneurysms, complication rates tend to be higher than with selective coiling because of the thrombogenicity of the devices and the need for dual antiplatelet medication with inherent risk in the postoperative period. Most operators are reluctant to use antiplatelet therapy in the setting of SAH because of the potential need for a ventriculostomy, the potential for infarction secondary to vasospasm, and the high likelihood of future invasive interventions. Therefore, stent placement is better avoided in acutely ruptured aneurysms in favor of endovascular techniques that do not mandate dual antiplatelet therapy or clipping.

With our patient selection for endovascular treatment with the WEB, the complication rate with this device was low, and the anatomic results were good. Complications consisted mainly of thromboembolic events. This may be related to the need for a more distal access with use of the WEB compared with coiling. With use of the WEB, a distal access-guiding catheter is indispensable to achieve a stable position of the microcatheter, and manipulations for distal access may promote thromboembolic events. In addition, the more frequent need of a triaxial approach with long sheets may have attributed as well. Of 9 patients with thromboembolic complications, 6 remained without clinical sequelae. In 5 patients with thrombi in the MCA or posterior communicating artery, thrombosuction was successful. This recent therapeutic achievement thus limited the clinical consequences of thromboembolic complications in our cohort. Procedural rupture with the WEB occurred only once, even though many aneurysms were small or very small. After deployment of the WEB, the bleeding stopped within a minute. Rupture with the WEB can only occur at a point when the undeployed WEB begins to exit the microcatheter. Once the WEB is partially deployed inside the aneurysm, the WEB is soft, and rupture can hardly occur.

An essential aspect of the WEB treatment was the sizing. Over- sizing the WEB seems crucial to obtain stable results. With oversizing, the WEB anchors itself against the aneurysm wall while bridging the neck completely. Oversizing causes compression of the WEB width, which in turn results in increased height, and one has to be sure that the aneurysm can accommodate this augmented height. Oversizing protects against displacement and overturning and possibly against compression of the WEB during follow-up. In small aneurysms, oversizing of approximately $1 \mathrm{~mm}$ will usually be sufficient, whereas in larger aneurysms, 2-mm oversizing is recommended for stable securing in the neck.

Anatomic and clinical results with the WEB were good; adequate occlusion (defined as complete occlusion or neck remnant) at 3-month angiographic follow-up was obtained in 96\% (71 of 74 patients with angiographic follow-up). Only 3 aneurysms had reopened at 3-month follow-up. Most important, during followup, no rebleeds occurred.

Our anatomic and clinical results in ruptured aneurysms treated with the WEB are better than in previous WEB series and also better than general results of coiling. ${ }^{10,22,31}$ The technique of WEB treatment has improved from the first WEB series by the introduction of lower profile microcatheters and imperative oversizing. Our aneurysm population includes small-neck aneurysms, and most aneurysms were small, with only a few larger than 10 $\mathrm{mm}$. Because reopening over time after coiling occurs more frequently in larger aneurysms, long-term results tend to be better in a population of small aneurysms.

Limitations of this study include self-reporting of angiographic results and the limited number of patients, keeping confidence intervals rather wide. A strong point of the study is the almost complete imaging follow-up with use of angiography.

\section{CONCLUSIONS}

WEB treatment of ruptured intracranial aneurysms is in our opinion feasible, effective, and safe. The WEB proved a valuable alternative to coils in many ruptured aneurysms regardless of location or neck size. Introduction of the WEB allowed us to refrain from the use of adjunctive stents and supporting balloons. Anticoagulation in the periprocedural period was not necessary. This was a great advantage in view of surgical procedures that were needed in patients with acutely ruptured aneurysms.

In view of our encouraging experiences with the WEB for ruptured aneurysms, this treatment has become first choice in our practice for ruptured aneurysms in sizes between 2 and $10 \mathrm{~mm}$. In larger aneurysms, coiling is the first option, and in exceptional cases, surgery is performed.

Disclosures: Willem Jan van Rooij—UNRELATED: Consultancy: Sequent Medical, Microvention, Comments: paid for proctoring and speakers bureau. Jo P. PelusoOTHER RELATIONSHIPS: MicroVention, Comments, Proctor. Charles B. MajoieUNRELATED: Consultancy: Stryker, Comments: Academisch Medisch Centrum received funds from Stryker for consultations by $\mathrm{CM}^{*}$; Grants/Grants Pending: TWIN Foundation, CVON/Dutch Heart Foundation*. *Money paid to the institution.

\section{REFERENCES}

1. Piotin M, Blanc R, Spelle L, et al. Stent-assisted coiling of intracranial aneurysms: clinical and angiographic results in 216 consecutive aneurysms. Stroke 2010;41:110-15 CrossRef Medline

2. Bartolini B, Blanc R, Pistocchi S, et al. "Y" and "X" stent-assisted 
coiling of complex and wide-neck intracranial bifurcation aneurysms. AJNR Am J Neuroradiol 2014;35:2153-58 CrossRef Medline

3. Chalouhi N, Jabbour P, Singhal S, et al. Stent-assisted coiling of intracranial aneurysms: predictors of complications, recanalization, and outcome in $\mathbf{5 0 8}$ cases. Stroke 2013;44:1348-53 CrossRef Medline

4. Chung J, Lim YC, Suh SH, et al. Stent-assisted coil embolization of ruptured wide-necked aneurysms in the acute period: incidence of and risk factors for periprocedural complications. J Neurosurg 2014; 121:4-11 CrossRef Medline

5. Bechan RS, Sprengers ME, Majoie CB, et al. Stent-assisted coil embolization of intracranial aneurysms: complications in acutely ruptured versus unruptured aneurysms. AJNR Am J Neuroradiol 2016; 37:502-07 CrossRef Medline

6. Lubicz B, Klisch J, Gauvrit JY, et al. WEB-DL endovascular treatment of wide-neck bifurcation aneurysms: short- and midterm results in a European study. AJNR Am J Neuroradiol 2014;35:432-38 CrossRef Medline

7. Colla R, Cirillo L, Princiotta C, et al. Treatment of wide-neck basilar tip aneurysms using the WEB II device. Neuroradiol J 2013;6:669-77 CrossRef Medline

8. Pierot L, Moret J, Turjman F, et al. WEB treatment of intracranial aneurysms: clinical and anatomic results in the French Observatory. AJNR Am J Neuroradiol 2016;37:655-59 CrossRef Medline

9. Pierot L, Spelle L, Molyneux A, et al. Clinical and anatomical follow-up in patients with aneurysms treated with the WEB device: 1 -year follow-up report in the cumulated population of 2 prospective, multicenter series (WEBCAST and French Observatory). Neurosurgery 2016;78:133-41 CrossRef Medline

10. Pierot L, Gubucz I, Buhk JH, et al. Safety and efficacy of aneurysm treatment with the WEB: results of the WEBCAST 2 study. AJNR Am J Neuroradiol 2017;38:1151-55 CrossRef Medline

11. Liebig T, Kabbasch C, Strasilla C, et al. Intrasaccular flow disruption in acutely ruptured aneurysms: a multicenter retrospective review of the use of the WEB. AJNR Am J Neuroradiol 2015;36:1721-27 CrossRef Medline

12. Bozzetto Ambrosi P, Gory B, Sivan-Hoffmann R, et al. Endovascular treatment of bifurcation intracranial aneurysms with the WEB SL/ SLS: 6-month clinical and angiographic results. Interv Neuroradiol 2015;4:462-69 CrossRef Medline

13. Pierot L, Costalat V, Moret J, et al. Safety and efficacy of aneurysm treatment with WEB: results of the WEBCAST study. J Neurosurg 2016;124:1250-56 CrossRef Medline

14. Sivan-Hoffmann R, Gory B, Riva R, et al. One-year angiographic follow-up after WEB-SL endovascular treatment of wide-neck bifurcation intracranial aneurysms. AJNR Am J Neuroradiol 2015;36: 2320-24 CrossRef Medline

15. Leyon JJ, Chavda S, Lamin S. Corking the WEB and coiling through a jailed microcatheter: WEB assisted coiling, a useful technique avoiding the use of stents in treating wide-necked large intracranial aneurysms. J Neurointerv Surg 2016;8:e18 CrossRef Medline

16. Gherasim DN, Gory B, Sivan-Hoffmann R, et al. Endovascular treatment of wide-neck anterior communicating artery aneurysms us- ing WEB-DL and WEB-SL: short-term results in a multicenter study. AJNR Am J Neuroradiol 2015;36:1150-54 CrossRef Medline

17. Caroff J, Mihalea C, Dargento F, et al. Woven Endobridge (WEB) Device for endovascular treatment of ruptured intracranial wideneck aneurysms: a single-center experience. Neuroradiology 2014; 56:755-61 CrossRef Medline

18. Armoiry X, Turjman F, Hartmann DJ, et al. Endovascular treatment of intracranial aneurysms with the WEB device: a systematic review of clinical outcomes. AJNR Am J Neuroradiol 2016;37:868-72 CrossRef Medline

19. Fiorella D, Molyneux A, Coon A, et al. Demographic, procedural and 30-day safety results from the WEB Intra-saccular Therapy Study (WEB-IT). J Neurointerv Surg 2017 Jan 17. [Epub ahead of print] CrossRef Medline

20. Muskens IS, Senders JT, Dasenbrock HH, et al. The Woven Endobridge device for treatment of intracranial aneurysms: a systematic review. World Neurosurg 2017;98:809-17.e1 CrossRef Medline

21. Herbreteau D, Bibi R, Narata AP, et al. Are anatomic results influenced by WEB shape modification? Analysis in a prospective, single-center series of 39 patients with aneurysms treated with the WEB. AJNR Am J Neuroradiol 2016;37:2280 -86 CrossRef Medline

22. Asnafi S, Rouchaud A, Pierot L, et al. Efficacy and safety of the Woven EndoBrigde (WEB) device for the treatment of intracranial aneurysms: a systemic review and meta-analysis. AJNR Am J Neuroradiol 2016;37:2287-92 CrossRef Medline

23. Lawson A, Goddard T, Ross S, et al. Endovascular treatment of cerebral aneurysms using the Woven EndoBridge technique in a single center: preliminary results. J Neurosurg 2017;126:17-28 CrossRef Medline

24. Clajus C, Strasilla C, Fiebig T, et al. Initial and mid-term results from 108 consecutive patients with cerebral aneurysms treated with the WEB device. J Neurointerv Surg 2017;9:411-17 CrossRef Medline

25. van Rooij WJ, Peluso JP, Bechan RS, et al. WEB treatment of ruptured intracranial aneurysms. AJNR Am J Neuroradiol 2016;37: 1679-83 CrossRef Medline

26. Caroff J, Mihalea C, Tuilier T, et al. Occlusion assessment of intracranial aneurysms treated with the WEB device. Neuroradiology 2016;58:887-91 CrossRef Medline

27. Pierot L. Letter: WEB aneurysm treatment: occlusion stability and “compression". Neurosurgery 2015;77:E666-67 CrossRef Medline

28. Cognard C, Januel AC. Remnants and recurrences after the use of the WEB intrasaccular device in large-neck bifurcation aneurysms. Neurosurgery 2015;76:522-30; discussion 530 CrossRef Medline

29. Brinjikji W, Cloft HJ, Kallmes DF. Difficult aneurysms for endovascular treatment: overwide or undertall? AJNR Am J Neuroradiol 2009;30:1513-17 CrossRef Medline

30. Janssen H, Berlis A, Lutz J, et al. State of practice: endovascular treatment of acute aneurysmal SAH in Germany. AJNR Am J Neuroradiol 2017;38:1574-79 CrossRef Medline

31. Ferns SP, Sprengers ME, van Rooij WJ, et al. Coiling of intracranial aneurysms: a systematic review on initial occlusion and reopening and retreatment rates. Stroke 2009;40:e523-29 CrossRef Medline 